\title{
The comparison of THMs and HAAs formation and speciation by chlorination and chloramination for different water sources
}

\author{
Kucukcongar S. ${ }^{1, *}$, Sevimli M.F. ${ }^{2}$ and Yel E. ${ }^{1}$ \\ 1Selcuk University, Environmental Engineering Department, Konya/Turkey \\ ${ }^{2}$ Karatay University, Civil Engineering Department, Konya/Turkey \\ Received: 29/11/2016, Accepted: 31/10/2017, Available online: 27/11/2017 \\ *to whom all correspondence should be addressed: e-mail: skucukcongar@yahoo.com
}

\begin{abstract}
Disinfection by-products (DBPs) can be controlled by using alternative disinfectants to chlorine, removing DBPs precursors prior to chlorination and removing DBPs after formed. Chloramine is widely used as an alternative disinfectant to chlorine usage. In this study to evaluate trihalomethanes (THMs) and haloacetic acids (HAAs) formation and speciation for Altinapa and Omerli dam water isolates after chlorination and choramination procedures at different $\mathrm{pH}$ values was aimed. Compared with chlorination, the formation of THMs was reduced by approximately 4-fold in chloramination for Omerli dam water. Total THM concentrations remained below detection limits in Altinapa isolate after chloramination. The dominant species were $\mathrm{CF}$ and followed by BDCM and CDBM in case of chlorination, and almost no BF formed. BF is the dominant specie together with $C F$ in case of chloramination, and no BDCM and CDBM formed at all pHs for Omerli dam water. HAA concentrations resulting from the use of chlorine were obtained 4.8-5.1 times higher from resulting from the use of chloramines at different $\mathrm{pH}$ values for Omerli Dam water; but this value was 5.5-8.7 for Altinapa Dam water. MCAA, DCAA and BCAA concentrations were a large part of the total HAA concentrations which obtained from chloramines usage for both isolates.
\end{abstract}

Keywords: Chlorination, chloramination, trihalomethanes, haloacetic acids.

\section{Introduction}

Chlorine has an important role in removing pathogens since the early 1900s and use of it as a disinfectant has come under scrutiny because of its potential to react with natural organic matter (NOM) and form chlorinated DBPs. Applied chlorine rapidly hydrolyses and hypochlorous acid $(\mathrm{HOCl})$ forms in the disinfection. This causes subsequent reactions resulting in the formation of DBPs. $\mathrm{HOCl}$ also oxidizes the bromide present in the water, which reacts readily to form brominated species of DBPs (Pourmoghaddas et al., 1993).

There has been an increasing concern about DBPs since Rook (1974) as well as Bellar and Lichtenberg (1974). THMs and HAAs are the most common DBPs (Krasner et al., 1989) and their distribution depends upon several factors such as quantity and characteristics of NOM, pH, SUVA, temperature, bromide concentration and chlorine/bromide ratio (Amy et al., 1987; Reckhow et al., 1990; Kitis, 2001; Nikolaou et al., 2004a; Nikolaou et al., 2004b; Kucukcongar et al., 2013). DBPs, especially THMs have been recognized as a carcinogenic halogenated byproduct and potentially hazardous to human health (Lee et al., 2004). The DBP regulations are based on evidence of their carcinogenic or other adverse human health effects. There are a lot of limitations imposed by EPA, EU and WHO for DBPs and maximum limits has been decreased in new revisions recently. However, there is not any limitation for them in many countries.

DBPs can be controlled by removing the DBP precursors, using of alternative disinfectants and removing the DBP itself. Because DBPs are difficult to remove once they are formed, control strategies typically focus on the first approach. The chloramines have the widest popularity due to its significant reduction of DBPs (especially THMs and HAAs) formation and its ability to provide residuals in water distribution system among alternative disinfectants to chlorine such as ozone, chlorine dioxide and other in drinking water treatment. In response to tightening health regulations regarding DBPs, many utilities have begun using monochloramine as a secondary form of water treatment (Diehl et al., 2000). This process, known as chloramination, is performed by combining of ammonia with chlorine for the purpose of forming monochloramine at a time that allows for maximum microbial inhibition with minimum DBP formation. Although generally not as an effective disinfectant as free chlorine, an advantage of chloramination is minimization of the formation of DBPs (Teng and Veenstra, 1996; Zhang et al., 2000, Guay et al., 2005, Hong et al., 2013). DBPs, such as THMs and HAAs are present at lower concentrations in chloraminated water samples than in chlorinated ones (Krasner et al., 1989; Cowman and Singer, 1996). Chloramine produced the same types of halogenated by-products as chlorine, but they were fewer in number and lower in concentration than for chlorine (Richardson et al., 2000). 
The effectiveness of chloramines to control DBP production depends upon a variety of factors, notable to chlorine-toammonia ratio, the point of addition of ammonia relative to that of chlorine, the extent of mixing, bromine concentration, $\mathrm{pH}$ etc. (Carlson and Hardy, 1998, Diehl et al., 2000, Qi et al., 2004, Tian et al., 2013). In this study, the effects of $\mathrm{pH}$ and disinfectant type as chlorine and chloramine on the formation and speciation of DBPs were determined on the water samples taken from the dams located in two different regions of Turkey.

\section{Materials and Methods}

Water samples were obtained from Altinapa and Omerli Dams, which have been used for the domestic and industrial water supply purposes in Konya and Istanbul cities in Turkey, respectively. The characteristics of the dam waters are presented in Table 1. All the dissolved organics and inorganics in the dam water samples were isolated using a laboratory scale reverse osmosis membrane (Filmtec, DOW Chemical Company, USA) which is composed of thin film composite membranes packed in a spiral wound configuration and were kept in the dark at $+4^{\circ} \mathrm{C}$.

Table 1. Water sample characteristics

\begin{tabular}{ccc}
\hline Parameter & $\begin{array}{c}\text { Altinapa } \\
\text { Dam Water }\end{array}$ & $\begin{array}{c}\text { Omerli Dam } \\
\text { Water }\end{array}$ \\
\hline $\mathrm{TOC}(\mathrm{mg} / \mathrm{L})$ & 2.48 & 3.40 \\
\hline $\mathrm{pH}$ & 8.26 & 7.15 \\
\hline Conductivity $(\mu \mathrm{S} / \mathrm{cm})$ & 367 & 280 \\
\hline Turbidity (NTU) & 5.48 & 4.0 \\
\hline $\mathrm{Br}^{-}, \mu \mathrm{g} / \mathrm{L}$ & $<20$ & 50 \\
\hline SUVA $_{254}, \mathrm{~L} / \mathrm{mg} . \mathrm{m}$ & 1.546 & 1.97 \\
\hline
\end{tabular}

The isolates were diluted with distilled water to adjust the NOM concentrations as TOC. After $\mathrm{pH}$ adjustment each was chlorinated with proper dosages according to UFC protocol (Summers et al., 1996) which simulates the average chlorination conditions in drinking water distribution systems and requires a free chlorine residual of $1.0 \pm 0.4$ $\mathrm{mg} / \mathrm{L}$ be maintained after 24 hours of contact time (Kitis, 2001). The original pH values of two isolates were 7.2. All samples were buffered with a phosphate buffer $(0.1 \mathrm{M})$ and adjusted to $\mathrm{pH} 6$ and 8 prior to chlorination/chloramination. Stock chlorine solution was prepared from sodium hypochlorite including 6-14\% free chlorine. Stock monochloramine solution was prepared by reacting of ammonium sulfate and sodium hypochlorite solutions $\left(\mathrm{Cl}_{2} / \mathrm{N}=2.5: 1\right)$.

After the incubation period, residual chlorine was measured by the DPD colorimetric method according to Standard Methods (APHA, 2005). The residual chlorine remaining in the bottles was quenched with sodium sulfite prior to analysis for DBPs. TOC analysis was performed by the high-temperature combustion method according to Standard Methods (APHA, 2005) using a Shimadzu TOC$\mathrm{V}_{\mathrm{CPH}}$ model TOC analyzer. THM analyses were carried out according to EPA Method 551.1 (EPA, 1995). The method includes liquid-liquid extraction and gas chromatography (GC) measurement. GC measurements were performed on an Agilent model 6890 GC equipped with Agilent model 7683 autosampler, $\mu$-electron capture detector (ECD) and HP-5MS capillary column under the GC conditions presented in Table 2. Calibration curves, obtained with standards from Supelco, USA, had at least seven points for four THM species; chloroform (CF), bromodichloromethane (BDCM), chlorodibromomethane (DBCM), bromoform (BF). HAA analyses were performed according to EPA Method 552.3 (EPA, 2003). This method includes liquid-liquid extraction, methylation and GC measurement. Gas chromatographic conditions were given in Table 2. Calibration curves were obtained with standards from AccuStandard, USA and had at least five points and nine HAA species; monochloroacetic acid (MCAA), monobromoacetic acid (MBAA), dichloroacetic acid (DCAA), trichloroacetic acid (TCAA), bromochloroacetic acid (BCAA), dibromoacetic acid (DBAA), bromodichloroacetic acid (BDCAA), chlorodibromoacetic acid (CDBAA) and tribromoacetic acid (TBAA).

Table 2. Gas chromatographic conditions for DBPs analyses

\begin{tabular}{|c|c|c|}
\hline & \multicolumn{2}{|c|}{ Common conditions for THMs and HAAs } \\
\hline Column & \multicolumn{2}{|c|}{$30 \mathrm{~m} \times 0.25 \mathrm{~mm}$ i.d. $\times 0.25 \mu \mathrm{m}$ film thickness } \\
\hline Injection mode & \multicolumn{2}{|c|}{ Splitless } \\
\hline Injector temperature & \multicolumn{2}{|r|}{$200^{\circ} \mathrm{C}$} \\
\hline Detector temperature & \multicolumn{2}{|r|}{$290^{\circ} \mathrm{C}$} \\
\hline & THMs & HAAs \\
\hline Carrier gas & High purity helium $(2.2 \mathrm{~mL} / \mathrm{min})$ & High purity helium (1.8 mL/min) \\
\hline Make-up gas & High purity nitrogen $(28.9 \mathrm{~mL} / \mathrm{min})$ & High purity nitrogen $(35.0 \mathrm{~mL} / \mathrm{min})$ \\
\hline Injection volume, $\mu \mathrm{L}$ & 1.0 & 2.0 \\
\hline $\begin{array}{l}\text { Oven temperature } \\
\text { program }\end{array}$ & $35^{\circ} \mathrm{C}(22 \mathrm{~min}), 10^{\circ} \mathrm{C} / \mathrm{min}$ to $125^{\circ} \mathrm{C}$ & $\begin{array}{l}35^{\circ} \mathrm{C}(10 \mathrm{~min}), 5^{\circ} \mathrm{C} / \mathrm{min} \text { to } 75^{\circ} \mathrm{C}(15 \mathrm{~min}), 5^{\circ} \mathrm{C} / \mathrm{min} \\
\text { to } 100^{\circ} \mathrm{C}(5 \mathrm{~min}), 5^{\circ} \mathrm{C} / \mathrm{min} \text { to } 135^{\circ} \mathrm{C}(2 \mathrm{~min})\end{array}$ \\
\hline
\end{tabular}

\section{Results and Discussion}

\subsection{The Effect of Usage of Chlorine and Chloramine on Residual Chlorine}

The UFC protocol implies the residual of $1.0 \pm 0.4 \mathrm{mg} / \mathrm{L}$ chlorine upon 24 hours contact time. Table 3 indicates the applied chlorine/chloramines dosage intervals and selected doses according to UFC protocol. These values were found for $4 \mathrm{mg} / \mathrm{L} \mathrm{TOC}$ and the same for $\mathrm{pH} 6,7.2$ and 
8. Many smaller chloramines doses are sufficient for the target residual. The difference between $1.5 \mathrm{mg} / \mathrm{L}$ and 1 $\mathrm{mg} / \mathrm{L}$ is much smaller than 6.3 and $1 \mathrm{mg} / \mathrm{L}$ indicating that much more chlorine is converted to DBPs as compared to chloramines. Change of residual chlorine with time under all these conditions are indicated in Fig 1.

Table 3. Applied and selected disinfectant dosages for UFC protocol

\begin{tabular}{ccccc}
\hline \multirow{2}{*}{ Water source } & \multicolumn{2}{c}{ Chlorine } & \multicolumn{2}{c}{ Chloramine } \\
\cline { 2 - 5 } & Applied interval, $\mathbf{~ m g / L}$ & Selected dose, $\mathbf{~ m g / L ~}$ & Applied interval, $\mathbf{m g} / \mathrm{L}$ & Selected dose, $\mathbf{~ m g / L ~}$ \\
\hline Altinapa & $2.8-6.3$ & 6.3 & $0.9-2.0$ & 1.5 \\
\hline Omerli & $3.7-4.9$ & 4.6 & $1.3-2.8$ & 1.5
\end{tabular}

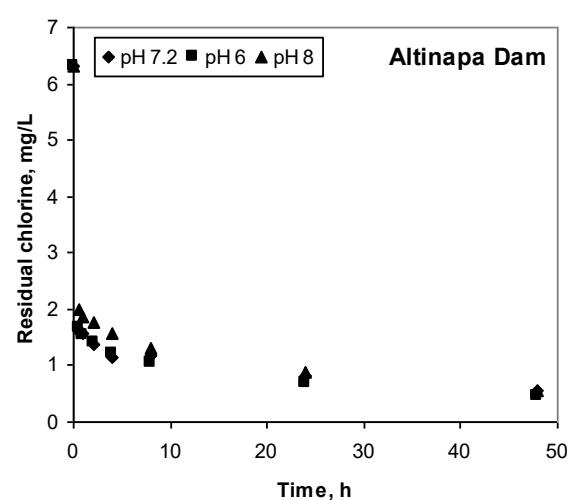

(a)

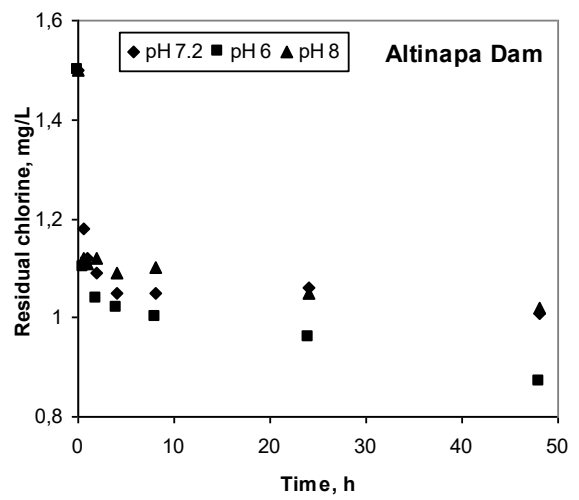

(b)
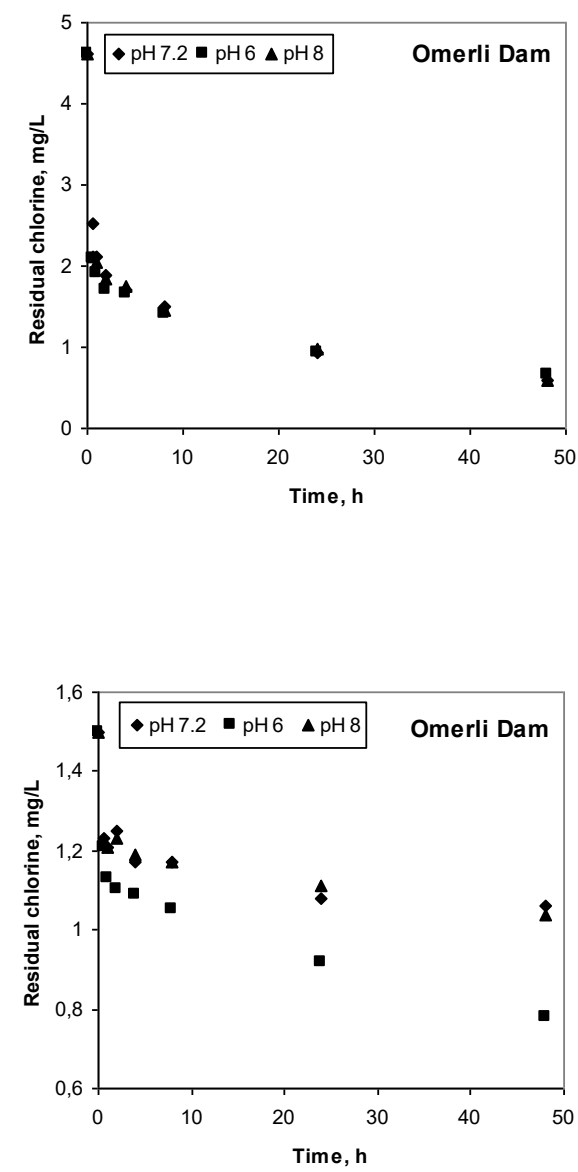

Figure 1. Change of residual chlorine after (a) chlorination and (b) chloramination at different pH for Altinapa and Omerli Dam water

In all $\mathrm{pH}$ values a rapid chlorine decrease was observed in the first 30 minutes for both isolates. In Altinapa isolate, totally $30-36 \%$ of chloramines were consumed in 24 hours and $21-27 \%$ of this was achieved in the first 30 minutes. Similarly, $26-38 \%$ of chloramines were consumed in Omerli isolate, $17-19 \%$ of it was in 30 minutes.

\subsection{The Effect of Usage of Chlorine and Chloramine on THM Formation}

Chlorine resulted in THM formation around 113-175 ppb in Omerli isolate and around 134-161 ppb in Altinapa isolate, whereas, total THM concentrations remained below 50 ppb in Omerli isolate (Fig.2) and below detection limits in Altinapa isolate. This considerable (approximately 4-fold) decrease clearly indicate the positive effect of chloramination upon chlorination, parallel to the literature (Norman et al., 1980; Krasner et al., 1989; Hwang et al., 2000; Zhang et al., 2000). The highest THMs were achieved at $\mathrm{pH} 7.2$ for both disinfectants and below and above this value, total THM levels decreased. Diehl et al. (2000) reported that, THM production followed the general trend of decreasing with increasing $\mathrm{pH}$. This trend is consistent with the premise that dichloramine, its decomposition products, or both are active in producing THMs at low $\mathrm{pH}$ and is the opposite of the trend found in free chlorination, which favors base-catalyzed THM formation mechanisms.

THM compounds at the end of 24 hours contact time were compared in Fig. 3 for chlorination and chloramination of Omerli isolate (TOC $4 \mathrm{mg} / \mathrm{L}$ ) at three different $\mathrm{pHs}$. The 
dominant species were $\mathrm{CF}$ and followed by BDCM and CDBM in case of chlorination, and almost no BF formed. On the other hand, $\mathrm{BF}$ is the dominant specie together with $\mathrm{CF}$ in case of chloramination, and no BDCM and CDBM formed at all $\mathrm{pHs}$.

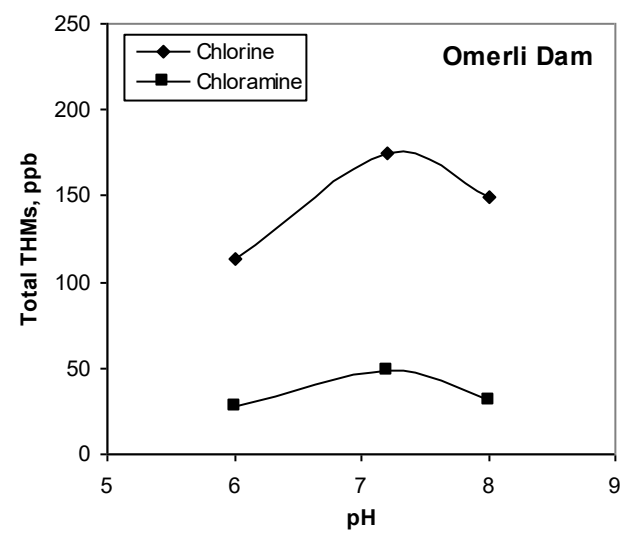

Figure 2. Change of total THM concentration after 24 hours at different $\mathrm{pH}$ for Omerli Dam water

Simpson and Hayes (1998) reported that, the speciation of THMs can vary depending on the nature of the source water. For example, in two drinking water sources, CF was the dominant compound with very little of the more highly brominated analogues present. However, in other two drinking water sources, there was a predominance of the brominated THMs. In their study (Simpson and Hayes, 1998) DBCM was almost always the major THM, followed by BF, BDCM and CF.

Diehl et al. (2000) reported that formation of THMs and HAAs decreased with an increase in the $\mathrm{pH}$ from 6 to 10 and with a decrease in the chlorine-to-ammonia nitrogen $(\mathrm{Cl}: \mathrm{N})$ ratio while increasing the bromide concentration increased the production of brominated compounds. The addition of $\mathrm{Br}^{-}$to Lake Austin water source caused more than a doubling of the total chlorine demand at $\mathrm{pH} 6$ and $\mathrm{Cl}_{2}$-to- $\mathrm{N}$ ratios at 5:1 and 7:1. The addition of $\mathrm{Br}^{-}$increased THM formation, especially at $\mathrm{pH} 6$.

The total chlorine demand indication of extensive reactions with $\mathrm{Br}^{-}$. The effect of $\mathrm{Br}^{-}$addition on total chlorine demand at the low $\mathrm{Cl}_{2} / \mathrm{N}$ ratio and $\mathrm{pH} 8$ and 10 was much less pronounced, implication reactions between dichloramine and $\mathrm{Br}^{-}$as the major cause of the increased chlorine demand at low $\mathrm{pH}(\mathrm{pH} 6)$ and moderate to high $\mathrm{Cl}_{2} / \mathrm{N}$ ratios (Diehl et al., 2000).

\subsection{Effect of Usage of Chlorine and Chloramine on HAA Formation}

The change of total HAA concentrations after chlorination and chloramination at different $\mathrm{pH}$ value for Altinapa Dam water isolate (4 mg/L TOC concentration) are given in Figure 4. The highest formation of HAA compounds were observed at $\mathrm{pH} 7.2$ and total HAAs concentration was decreased to $25-30 \mu \mathrm{g} / \mathrm{L}$ at $\mathrm{pH} 6$ and 8 . HAA concentrations were obtained similar at $\mathrm{pH} 6$ and $\mathbf{7 . 2}$ for Omerli Dam water; but HAA concentrations were decreased with increasing $\mathrm{pH}$ to 8 (Fig. 4).
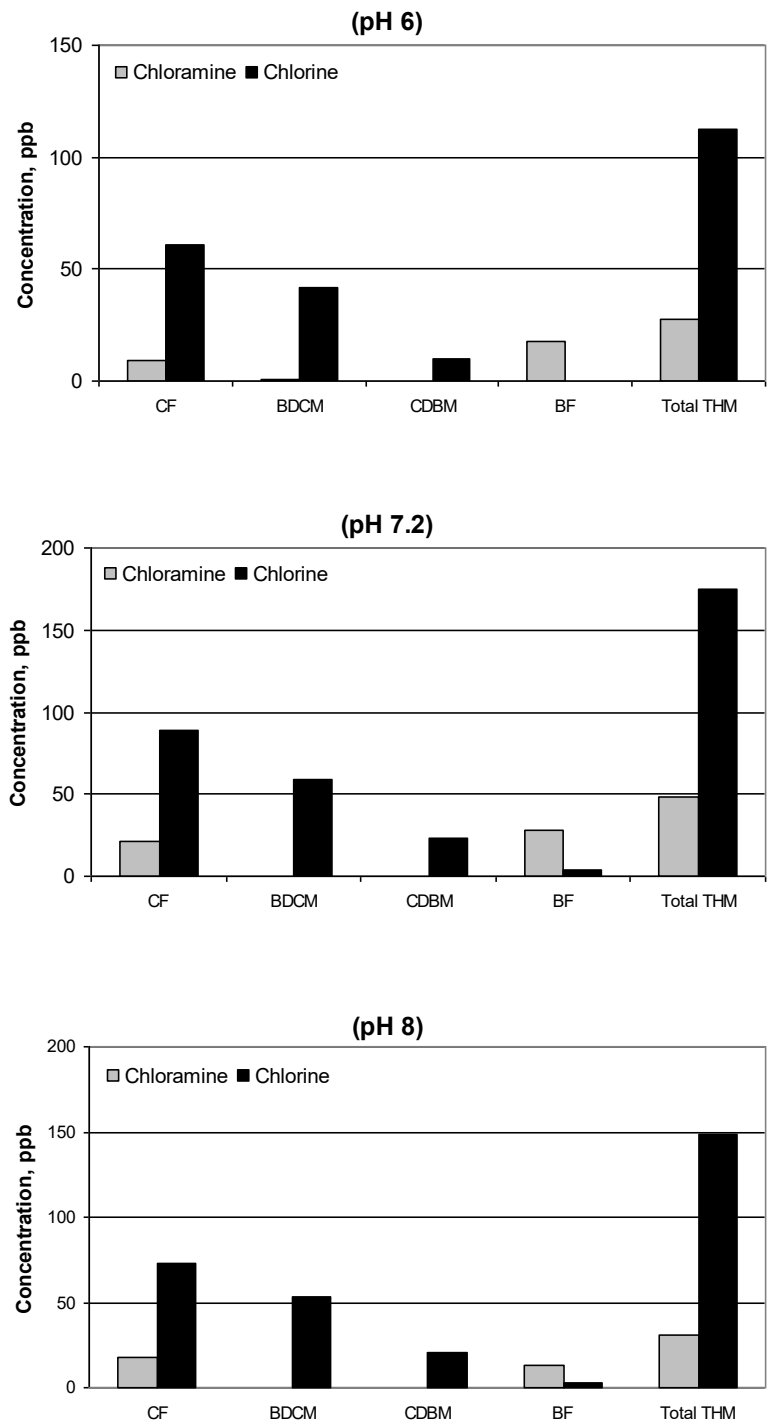

Figure 3. Distribution of THM species after chlorination and chloramination at different $\mathrm{pH}$ for Omerli Dam water.

For both isolates, the use of chloramine at different $\mathrm{pH}$ values was caused similar HAA concentrations. HAA concentrations resulting from the use of chlorine were obtained 4.8-5.1 times higher from resulting from the use of chloramines at different $\mathrm{pH}$ values for Omerli Dam water; but this value was 5.5-8.7 for Altinapa Dam water.

Diehl et al. (2000) reported that, the HAA6 concentration decreased as the $\mathrm{pH}$ increased, and the $\mathrm{Cl}_{2} / \mathrm{N}$ ratio decreased. Higher initial $\mathrm{Cl}: \mathrm{N}$ ratios always resulted in higher HAA yields. Increasing bromide concentrations shifted HAA yields towards bromine-containing ones and increased the production of total HAAs and brominecontaining HAAs, together with lower yields of the nonbromine HAAs (Zhang et al., 2000; Qi et al., 2004). 

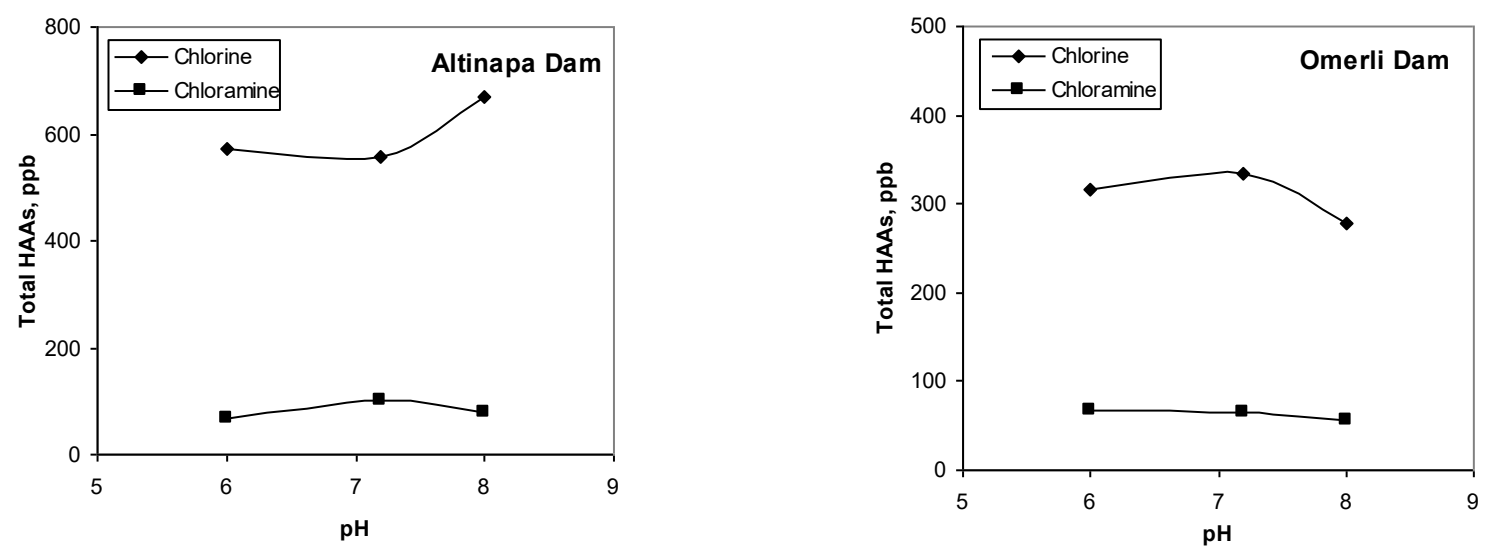

Figure 4. Change of total HAA concentration after 24 hours at different pH for Altinapa and Omerli Dam water

HAA species consisting from the use of chlorine and chloramine at different $\mathrm{pH}$ values for Altinapa Dam water isolate (4 mg/L TOC concentration) were given in Fig. 5. In chloramines studies, isolates which containing $4 \mathrm{mg} / \mathrm{L} \mathrm{TOC}$ concentration were used and total HAA concentrations were lower than $100 \mu \mathrm{g} / \mathrm{L}$, 24 hours after from chlorination process for all $\mathrm{pH}$ values. BDCAA wasn't found at all $\mathrm{pH}$ values in chloramination studies.

HAA species consisting from the use of chlorine and chloramine at different $\mathrm{pH}$ values for Omerli Dam water isolate $(4 \mathrm{mg} / \mathrm{L}$ TOC concentration) were given in Fig. 5 . HAA concentrations resulting from the use of chloramine were obtained \% 20-21 from the use of chlorine. MCAA, DCAA and BCAA concentrations were a large part of the total HAA concentrations which obtained from chloramines usage for both isolates. These were dominant HAA species for chlorine usages as a disinfectant.

Chloramination is an effective alternative disinfection method to chlorine usage for to decrease HAA formation (Norman et al., 1980; Krasner et al., 1989; Cowman and Singer, 1996; Hwang et al., 2000; Zhang et al., 2000). The usage of chloramines generally suppresses to trihalogenated HAA species formation (Cowman and Singer, 1996). Zhang et al. (2000) reported that, the highest HAA concentrations were formed during chlorination, which produced TCAA and DCAA as the predominant species; and in the chloraminated sample, DCAA was the predominant species, much higher than that of TCAA. In our study dihalogenated HAA species was occurred as dominant species for chlorine and chloramines usage in both Altinapa and Omerli Dam isolates.

When comparing the HAA speciation resulting from chlorination and chloramination, Cowman and Singer (1996) reported that in the chlorinated samples, the trihalogenated and dihalogenated HAAs are the predominant species, constituting about $95 \%$ of the total HAA concentration. In contrast the speciation in chloraminated waters, the dihalogenated species were the principal species formed, while the trihalogenated species were the minor species. Diehl et al. (2000) reported that, in all cases, the dihalogenated species were the dominant HAAs, comprising 100 percent of the HAA6 concentration in more than 70 percent of the samples and more than 80 percent of the HAA6 concentration in all but one sample. The relative mix of chlorinated and brominated dihaloacetic acids (DXAAs) varied with $\mathrm{Br}^{-}$concentration. The TCAA and MBAA concentrations were less than the detection limit in all samples. Clearly, chloramines preferentially form DXAAs, resulting in a much different pattern of HAA formation than seen with chlorination, in which formation of trihaloacetic acids (TXAAs) typically exceeds that of the DXAAs (Cowman and Singer, 1996). Chloramination increases the levels of DXAA (Goslan et al., 2009).

\section{Conclusion}

The main conclusions were as follows:

A A rapid chlorine decrease was observed in the first 30 minutes in all pH values for Altinapa and Omerli isolates.

> Total THM concentrations remained below $50 \mathrm{ppb}$ in Omerli isolate and below detection limits in Altinapa isolate after chloramination. Approximately 4-fold decrease clearly indicates the positive effect of chloramination upon chlorination for total THMs formation.

> The highest THMs were achieved at pH 7.2 for both disinfectants and below and above this value, total THM levels decreased for Omerli dam water.

> The dominant species were $\mathrm{CF}$ and followed by $B D C M$ and CDBM in case of chlorination, and almost no $\mathrm{BF}$ formed. On the other hand, $\mathrm{BF}$ is the dominant specie together with $\mathrm{CF}$ in case of chloramination, and no BDCM and CDBM formed at all $\mathrm{pH}$ s for Omerli dam water.

> The highest formation of HAA compounds were observed at $\mathrm{pH} 7.2$ and total HAAs concentration was decreased to $25-30 \mu \mathrm{g} / \mathrm{L}$ at pH 6 and 8 . HAA concentrations were obtained similar at $\mathrm{pH} 6$ and 7.2 for Omerli Dam water; but HAA concentrations were decreased with increasing $\mathrm{pH}$ to 8 .

> HAA concentrations resulting from the use of chlorine were obtained 4.8-5.1 times higher from 
resulting from the use of chloramines at different $\mathrm{pH}$ values for Omerli Dam water; but this value was 5.5-8.7 for Altinapa Dam water.

In chloramines studies, isolates which containing $4 \mathrm{mg} / \mathrm{L}$ TOC concentration were used and total HAA concentrations were lower than $100 \mu \mathrm{g} / \mathrm{L}, 24$ hours after from chlorination process for all $\mathrm{pH}$ values. BDCAA wasn't found at all $\mathrm{pH}$ values in chloramination studies.
HAA concentrations resulting from the use of chloramine were obtained \% 20-21 from the use of chlorine. MCAA, DCAA and BCAA concentrations were a large part of the total HAA concentrations which obtained from chloramines usage for both isolates. These were dominant HAA species for chlorine usages as a disinfectant.
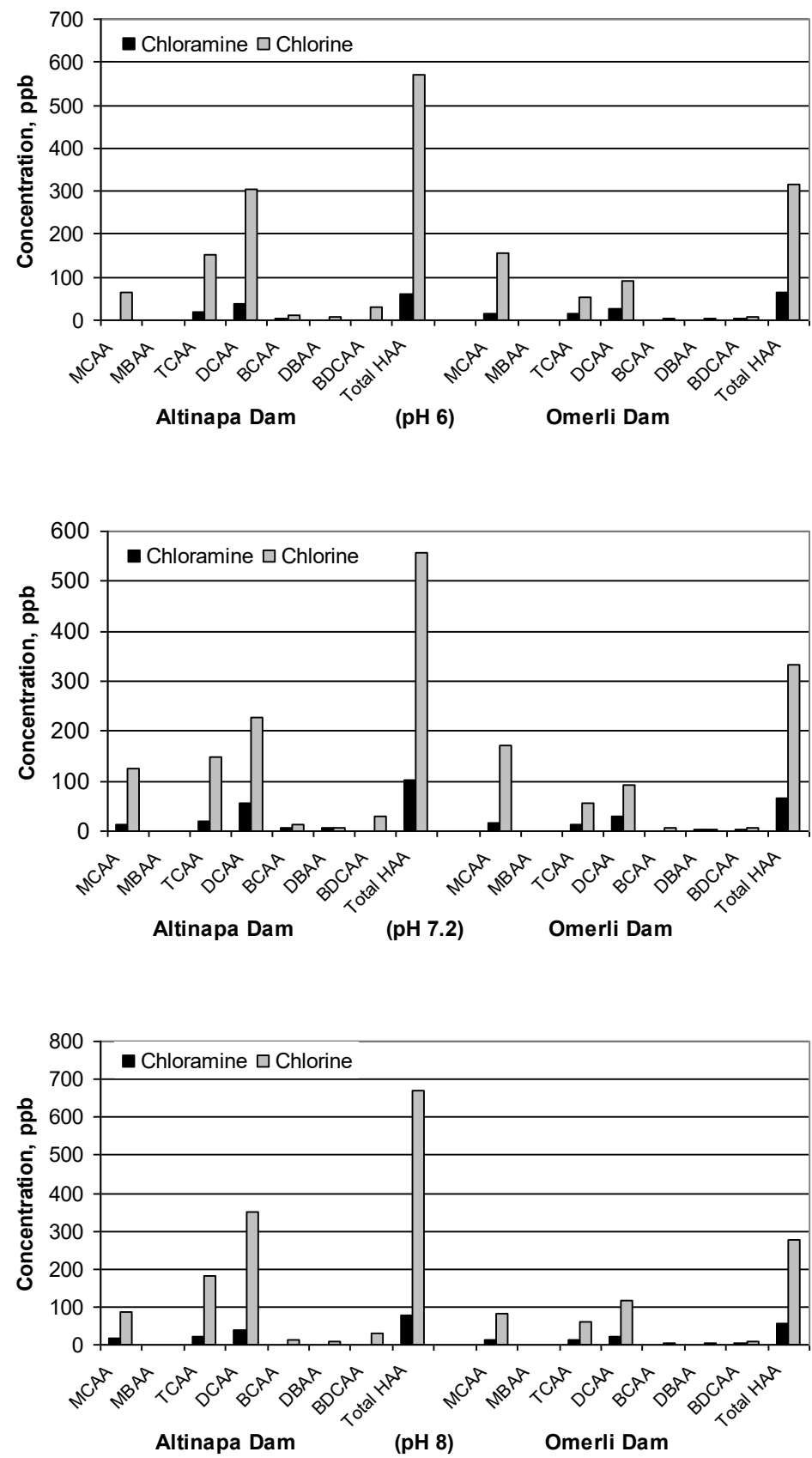

Figure 5. Distribution of HAA species after chlorination and chloramination at different $\mathrm{pH}$ for Altinapa and Omerli Dam water

\section{Acknowledgements}

This study is financially supported by the Scientific and Technological Research Council of Turkey (TUBITAK) under grant no 104I123 and Selçuk University Scientific Research Projects (BAP) Coordinating Office under grant no 05101022.

\section{References}

Amy G.L., Chadik P.A. and Chowdhury Z.K. (1987), Developing models for predicting trihalomethane formation potential and kinetics, J. Am. Water Work Ass., 79, 89-97. 
APHA, AWWA, WEF (2005), Standard Methods for the Examination of Water and Wastewater, $21^{\text {st }}$ Edition, Washington DC.

Bellar T.A. and Lichtenberg J.J. (1974), Determining volatile organics at microgram-per-liter levels by gas chromatography, J. Am. Water Work. Ass., 66, 739-744.

Carlson M. and Hardy D. (1998), Controlling DBPs with monochloramine, AWWA Journal, 90(2), 96-106.

Cowman G.A and Singer P.C. (1996), Effect of bromide ion on haloacetic acid speciation resulting from chlorination and chloramination of aquatic humic substances, Environ. Sci. Technol., 30, 16-24.

Diehl A.C., Speitel G.E., Symons J.M., Krasner S.W., Hwang C.J. and Barrett S.E. (2000), DBP formation during chloramination, J. Am. Water Works Assoc., 92, 6, 76-90.

EPA (1995), Method 551.1, Determination of Chlorination Disinfection By-Products, Chlorinated Solvents and Halogenated Pesticides/Herbicides in Drinking Water by Liquid-Liquid Extraction and Gas Chromatography with Electron-Capture Detection, Office of Research and Development, Ohio.

EPA (2003), Method 552.3, Determination of Haloacetic Acids and Dalapon in Drinking Water by Liquid-Liquid Microextraction, Derivatization and Gas Chromatography with Electron Capture Detection, Office of Ground Water and Drinking Water, Ohio.

Goslan E.H., Krasner S.W., Bower M., Rocks S.A., Holmes P., Levy L.S. and Parsons S.A. (2009), A comparison of disinfection byproducts found in chlorinated and chloraminated drinking waters in Scotland, Water Res., 43, 4698-4706.

Guay C., Rodriguez M. and Sérodes J. (2005), Using ozonation and chloramination to reduce the formation of trihalomethanes and haloacetic acids in drinking water, Desalination, 176, 229-240.

Hong H., Xiong Y., Ruan M., Liao F., Lin H. and Liang Y. (2013), Factors affecting THMs, HAAs and HNMs formation of Jin Lan reservoir water exposed to chlorine and monochloramine, Science of The Total Environment, 444, 196-204.

Hwang C.J., Sclimenti M.J. and Krasner S.W. (2000), Disinfection by-product formation reactivities of natural organic matter fractions of a low-humic water, In: Natural Organic Matter and Disinfection By-Products-Characterization and Control in Drinking Water, Barrett S.E., Krasner S.W., Amy G.L. (Eds.), 173-187, American Chemical Society, Washington, DC.

Kitis M. (2001), Probing Chlorine Reactivity of Dissolved Organic Matter for Disinfection By-Product (DBP) Formation: Relations with Specific Ultraviolet Absorbance (SUVA) and Development of the DBP Reactivity Profile, Ph.D. Thesis, Clemson University.

Krasner S.W., McGuire M.J., Jacangelo J.G., Patania N.L., Regan K.M. and Marco A.E. (1989), Occurrence of disinfection byproducts in US drinking water, J. Am. Water Work. Ass., 81(8), 41-53.

Kucukcongar S., Sevimli M.F. and Yel E. (2013), DBP formation and speciation in a central Anatolian dam water depending on $\mathrm{pH}$, TOC level, fraction and chlorine dose, Global NEST Journal, 15(4), 447-456.

Lee S.C., Guo H., Lam S.M.J. and Lau S.L.A. (2004), Multipathway risk assessment on disinfection by-products of drinking water in Hong Kong, Environmental Research, 94, 47-56.
Nikolaou A.D., Golfinopoulos S.K., Arhonditsis G.B., Kolovoyiannis V. and Lekkas T.D. (2004a), Modeling the formation of chlorination by-products in river waters with different quality, Chemosphere, 55, 409-420.

Nikolaou A.D., Golfinopoulos S.K., Lekkas T.D. and Kostopoulou M.N. (2004b), DBP levels in chlorinated drinking water: effect of humic substances, Environmental Monitoring and Assessment, 93, 301-319.

Norman T.S., Harms L.L. and Looyenga R.W. (1980), The use of chloramines to prevent trihalomethanes formation, J. Am. Water Work Ass., 82, 176-180.

Pourmoghaddas H., Stevens A.A., Kinman R.N., Dressman R.C., Moore L.A. and Ireland J.C. (1993), Effect of bromide ion on formation of HAAs during chlorination, J. Am. Water Work. Ass., 85(1), 82-87.

Qi Y., Shang C. and Lo I.M.C. (2004), Formation of haloacetic acids during monochloramination, Water Res., 38, 2375-2383.

Reckhow D.A., Singer P.C. and Malcolm R.L. (1990), Chlorination of humic materials: by-product formation and chemical interpretations, Environ.Sci.Technol., 24(11), 1655-1664.

Richardson S.D., Thruston A.D., Caughran T.V., Chen P.H., Collette T.W., Schenck K.M., Lykins B.W., Rav-Acha C. and Glezer V. (2000), Identification of new drinking water disinfection byproducts from ozone, chlorine dioxide, chloramines and chlorine, Water, Air and Soil Pollution, 123, 95-102.

Rook J.J. (1974), Formation of haloforms during chlorination of natural waters, Water Treatment Examination, 23, 234-243.

Simpson K.L. and Hayes K.P. (1998), Drinking water disinfection by-products: an Australian perspective, Water Res., 32(5), 1522-1528.

Summers R.S., Hooper M.S., Shukairy H.M., Solarik G. and Owen D. (1996), Assessing DBP yield: uniform formation conditions, J. Am. Water Work. Ass., 88(6), 80-93.

Teng H. and Veenstra J.N. (1996), A study of disinfection byproducts formed using four alternative disinfectants as a function of precursor characteristics, In: Disinfection ByProducts in Water Treatment, The Chemistry and Their Formation and Control, Minear R.A., Amy G.L. (Eds.), 371-392, Lewis Publishers.

Tian C., Liu R., Guo T., Liu H., Luo Q. and Qu J. (2013), Chlorination and chloramination of high-bromide natural water: DBPs species transformation, Separation and Purification Technology, 102, 86-93.

Zhang X., Echigo S., Minear R.A. and Plewa M.J. (2000), Characterization and comparison of disinfection by-products of four major disinfectants, In: Natural Organic Matter and Disinfection By-Products-Characterization and Control in Drinking Water, Barrett, S.E., Krasner, S.W., Amy, G.L. (Eds.), American Chemical Society, Washington, DC. 